\title{
PRÁTICAS INCLUSIVAS: EXPERIÊNCIA FORMATIVA COM PROFESSORES DA REDE MUNICIPAL DE ENSINO
}

Ana Mayra Samuel da Silva', Danielle Aparecida do Nascimento dos Santos ${ }^{2}$, José Eduardo de Oliveira Evangelista Lanuti ${ }^{3}$, Ana Virginia Isiano Lima', Elisa Tomoe Moriya Schlünzen'.

'Universidade Estadual Paulista - UNESP, Programa de Pós-Graduação em Educação, Presidente Prudente, SP. ${ }^{2}$ Universidade do Oeste Paulista - UNOESTE, Programa de Pós-Graduação em Educação, Presidente Prudente, SP. ${ }^{3}$ Universidade Estadual de Campinas - UNICAMP, Programa de Pós-Graduação em Educação, Campinas, SP. E-mail: ana.mayra.ss@gmail.com, anaisianolima@gmail.com, elisa@fct.unesp.br, dulanuti@gmail.com, danielle@unoeste.br.

Agência de fomento: Coordenação de Aperfeiçoamento de Pessoal de Nível Superior (CAPES)

\section{RESUMO}

Para que a inclusão escolar se efetive, a escola como um todo deve se preparar para desenvolver um trabalho pedagógico capaz de valorizar as diferenças. Para tanto, um dos aspectos essenciais é o investimento na formação de professores, uma vez que, para incluir, o ensino precisa ser repensado. Neste artigo será descrita uma experiência formativa vivenciada junto aos professores de uma rede municipal de educação, visando abordar com eles os temas políticas e práticas inclusivas. Participaram dessa experiência formativa aproximadamente noventa professores. A experiência formativa, realizada em uma formação proposta pela secretaria de educação do município, em dois dias, proporcionou aos professores: conhecer as políticas educacionais em vigência, que podem auxiliá-los quanto aos princípios da inclusão, refletir sobre sua própria prática, reconhecer as possibilidades da escola pública para a inclusão de todos os estudantes.

Palavras-chave: Escola Pública, Formação de Professores, Educação Inclusiva, Práticas Pedagógicas.

\section{INCLUSIVE PRACTICES: TRAINING EXPERIENCE WITH TEACHERS OF THE MUNICIPAL TEACHING NETWORK}

\begin{abstract}
For school inclusion becomes effective, the school as a whole must be prepared to develop a teaching job able to value differences. Therefore, a key aspect is investment in teacher training, since, to include teaching needs to be rethought. a formative experience lived with teachers of a municipal education network, aimed at addressing the political issues with them and inclusive practices in this article will be described. Participated in this formative experience about ninety teachers. Formative experience held in a training proposed by the municipal education department, in two days, gave the teachers: to know the educational policies in force, that can help them on the principles of inclusion, reflect on their own practice, recognize the possibilities of public school for the inclusion of all students.
\end{abstract}

Keywords: Public School, Teacher Education, Inclusive Education, Pedagogical Practices. 


\section{INTRODUÇÃO}

A Constituição Federal Brasileira de 1988 inaugurou, no âmbito educacional, o direito pleno das pessoas com deficiência ${ }^{1}$ à sua inclusão com qualidade, nas escolas comuns de ensino regular. Em seu artigo 205 a educação é apresentada como direito de todos, dever do Estado e da família, visando o pleno desenvolvimento da pessoa, seu preparo para o exercício da cidadania e sua qualificação para o trabalho. Nesse sentido, é possível inferir que a inclusão deve ser para todos, indistintamente.

Apesar de a inclusão escolar ser amparada por lei, ainda é um assunto controverso no âmbito da prática. As interpretações equivocadas sobre o que é incluir têm feito com que alguns estudantes sejam, muitas vezes, integrados e não incluídos no processo educacional formal e regular.

A inclusão escolar pode ser entendida como o processo em que todos os estudantes, sem distinções, passam a ter as mesmas oportunidades para aprender a partir de suas possibilidades, inseridos no mesmo contexto, de modo que as suas necessidades e os seus interesse sejam o ponto de partida para o planejamento das atividades escolares. Nesse sentido, a inclusão deve ser para todos e provoca um movimento de mudança nas práticas de ensino!

Para que a inclusão se efetive no meio educacional, a escola deve considerar a necessidade de se preparar para valorizar as diferenças. Para que todos os estudantes sejam acolhidos e atendidos de acordo com as suas necessidades e especificidades, bem como valorizados na sua essência, o objetivo central das práticas de ensino deve ser o de conhecer os estudantes em sua individualidade, considerando a potencialidade de se aprender com o outro.

A partir da Constituição Federal Brasileira de 1988, outros dispositivos legais foram, também, amparando a inclusão escolar de todos os estudantes no processo educacional formal e regular. Conforme a Política Nacional de Educação Especial na Perspectiva da Educação Inclusiva (MEC, 2008) para que todos sejam incluídos, se faz uma necessária uma mudança nos métodos, estratégias e currículos.

A partir desse cenário político, surge um grande desafio para a educação brasileira: a efetivação de uma escola inclusiva que valoriza as diferenças, que proporciona aos seus estudantes um ensino de qualidade, que possa garantir condições de acesso e permanência necessárias para que todos aprendam.

Sendo assim, uma das coisas que se faz necessária é formar esse professor a fim de superar esse importante desafio da educação brasileira: a inclusão escolar. O novo paradigma educacional brasileiro congrega importantes mudanças estruturais da escola comum de ensino regular, que deve pensar nas especificidades de todos os estudantes em termos não só de acesso à escolarização, quanto de oportunidades de aprendizado e de desenvolvimento de seus potenciais cognitivos, sociais, políticos, afetivos e emocionais.

De acordo com Weiss (2003 apud CASTRO e FACION 2009, p. 169),

Para superar as limitações de uma prática repetitiva, além da discussão sobre a promoção de um professor reflexivo e crítico, é necessário questionar as possibilidades de exercício de cidadania, dentro de uma sociedade excludente, por um grupo de pessoas identificadas como "especiais", seja por suas características notadamente diferentes, seja porque trabalham ou convivem com os assim identificados. Dessa forma, a reflexão do professor sobre o seu papel social deve incluir o que significa ser professor.

Castro e Facion (2009) afirmam que, para tanto, a formação dos professores deve propor a criação de espaços que permitam a participação e a reflexão sobre a ação desse profissional, a fim

\footnotetext{
${ }^{1}$ Física, visual, auditiva e intelectual, transtornos do espectro autista e altas habilidades/superdotação.
} 
que de se possa compreender, aprender e adaptar à essa nova realidade da inclusão. Assim, podemos defender a ideia de que a formação de professores deve se basear "[...] na aprendizagem da prática, para a prática e a partir da prática" (SACRISTÁN e GÓMEZ, 2000, p. 363).

Desse modo, para Glat (2000, p. 19)

A qualificação técnica de boa qualidade dos futuros profissionais, [...] deve ser revista no sentido de prepara-los para concretizar o ideal democrático de oportunizar a educação básica a todos os alunos, quebrando barreiras e limitações de toda ordem, que geram segregacionismo e discriminações.

Nessa perspectiva, o ensino regular assume o compromisso de desenvolver e promover um processo de ensino e de aprendizagem de qualidade a todos os estudantes que frequentam a escola comum, independentemente de suas dificuldades ou deficiências.

Sabe-se que a aprendizagem da docência, a construção de saberes docentes, não se encerra na formação inicial. É praticando diariamente o ato de ensinar e refletindo sobre o próprio trabalho pedagógico que podem ser construídas ações capazes de incluir todos os estudantes. Portanto, é necessário investir na formação continuada de profissionais envolvidos com a educação, para que possam se sentir plenamente preparados para atuar com os todos os estudantes nesse ambiente.

Considerando todas essas premissas, o artigo propõe a reflexão sobre uma experiência formativa realizada junto aos gestores e professores da rede municipal de educação de um município do interior paulista, visando abordar o tema políticas e práticas inclusivas.

\section{METODOLOGIA}

A abordagem para o desenvolvimento da reflexão sobre a experiência de formação é qualitativa. Conforme Richardson (2012, p. 80)

Os estudos que empregam uma metodologia qualitativa podem descrever a complexidade de determinado problema, analisar a interação de certas variáveis, compreender e classificar processos dinâmicos vividos por grupos sociais, contribuir no processo de mudança de determinado grupo e possibilitar, em maior nível de profundidade, o entendimento das particularidades do comportamento dos indivíduos.

O autor ainda justifica que por meio dessa abordagem é possível entender a natureza de um fenômeno social e propor soluções práticas.

A partir da abordagem qualitativa, a experiência formativa realizada prevê a análise das discussões realizadas, no âmbito da formação, sobre os elementos que possibilitam e impossibilitam que os princípios da Educação Inclusiva se efetivem naquele município, buscando alternativas e soluções para o fenômeno.

\section{Sujeitos da Pesquisa}

A experiência formativa foi realizada como um elemento presente na pesquisa de Mestrado intitulada "Educação Inclusiva na Perspectiva do Trabalho Colaborativo: Desafio de uma Escola Pública", submetida ao Comitê de Ética em Pesquisa, número do CAAE: 10206912.2.0000.5402.

A experiência formativa ocorreu no âmbito publicada secretaria municipal de educação de um município no interior do oeste paulista, sendo os participantes 60 professores de classe comum do ensino regular e 20 gestores escolares.

Pensando em atender as necessidades formativas da equipe gestora e dos professores da secretaria, organizamos colaborativamente dois períodos de formação. Participaram desta 
experiência formativa professores de sete escolas públicas municipais, compreendendo Educação Infantil, Ensino Fundamental ciclo I e ciclo II.

\section{INSTRUMENTOS E COLETA DE DADOS}

Empregamos a observação participante que permitiu a coleta de dados para examinar os fenômenos estudados. Segundo Lakatos e Marconi (2010, p. 176), "o observador sabe o que procura e o que carece de importância em determinada situação; deve ser objetivo, reconhecer possíveis erros e eliminar sua influência sobre o que vê ou recolhe". A observação participante foi registrada mediante os documentos presentes na organização da experiência formativa até sua efetivação, usando portfólio de registro, que será posteriormente agregado aos instrumentos de coleta, seleção e análise de dados da pesquisa de mestrado supracitada.

Com isso, apresentamos a seguir uma breve descrição e análise sobre a experiência formativa.

\section{RESULTADOS}

A partir da observação participante empregada como procedimento para a coleta de dados durante a experiência formativa, inicialmente relatamos que emergiu o desejo da equipe gestora de uma escola da rede municipal, em receber orientações de profissionais da educação que desenvolvem pesquisas sobre Educação Especial na perspectiva da Educação Inclusiva. Inicialmente o planejamento dessa ação previa a realização de palestra na unidade escolar durante a Hora de Trabalho Pedagógico Coletivo (HTPC).

A pesquisadora convidou dois profissionais para realizar a formação com os professores da unidade escolar, campo da pesquisa de mestrado. Compreendendo que a experiência formativa seria extremamente importante para todos os profissionais da educação da rede municipal de ensino, a equipe gestora e pesquisadora entraram em contato com a Secretaria Municipal de Educação com o intuito de estender o convite à todas as escolas, que de imediato o aceitou a proposta.

Dessa forma, foi organizado o evento formativo, com o tema "Educação Inclusiva". Os pesquisadores vinculados à Universidade do Oeste Paulista (Unoeste) e à Universidade Estadual Paulista (Unesp), bem como à Universidade Estadual de Campinas (Unicamp), Professora Doutora Danielle Aparecida do Nascimento dos Santos e Professor Mestre José Eduardo de Oliveira Evangelista Lanuti, foram orientados, pela pesquisadora e secretária de educação, a abordar as políticas públicas de educação especial na perspectiva da educação inclusiva, apresentando assim, a inclusão dentro das possibilidades das escolas públicas; e para apresentar práticas pedagógicas para o ensino de matemática em uma perspectiva inclusiva.

A palestra intitulada "Práticas Educacionais Inclusivas: legislação e ação", apresentada pela Professora Doutora, abordou os principais marcos legais sobre a Educação Especial na perspectiva da Educação Inclusiva, bem como as principais ações que as escolas públicas podem desenvolver para alcançar o patamar de uma escola inclusiva, que valorize e potencialize as diferenças de cada estudante.

Durante a palestra os professores participantes levantaram diversas questões polêmicas, por considerarem as políticas públicas de inclusão escolar utópicas, geradas principalmente pela falta de conhecimento de programas de ação do Ministério da Educação (MEC) voltados à formação docente e à implementação de recursos e estratégias voltados aos estudantes com deficiências matriculados nas escolas.

Dentre os fatores alegados pelos professores participantes, contra as perspectivas presentes na legislação, afirmaram não estar preparados para trabalhar com estudantes com deficiências, dificuldades de aprendizagem severas, e diferenças marcantes, pois não tiveram 
disciplinas durante a licenciatura, e não possuem verba e nem tempo para realizarem cursos na área.

A palestrante fez com que refletissem sobre essa fala, o que gerou certo desconforto, pois, perceberam, que incluir não depende totalmente da formação inicial, mas sim da prática diária, bem como da compreensão de que ensinar não pode partir da perspectiva de que todos vão aprender do mesmo jeito. Ou seja, refletiram que a licenciatura em si, não garante que aprendam a lidar com as dificuldades enfrentadas no interior de uma escola pública, e nem como incluir estudantes com as características supracitadas. Incluir significa aceitar que as pessoas podem aprender segundo as suas capacidades e especificidades, desde que sejam dadas condições para que isso ocorra, ou seja, os métodos de ensino precisam ser revistos.

O desconforto gerado, fez com que fosse atingido o objetivo da experiência formativa, pois, a problematização das questões levantadas pelos professores favoreceu à reflexão do grupo em relação ao que podem fazer para incluir os estudantes. Auxiliou na reflexão que queríamos proporcionar aos participantes: os estudantes com deficiência e dificuldades de aprendizagem são desafios, e, cabe a cada profissional da educação superar esse desafio da melhor maneira possível, tanto para o estudante como para si mesmo, e, só saberemos superá-lo com nossa própria prática enquanto docente. Sempre lembrando que para chegar no ideal, devemos trabalhar com o que é possível.

A palestra intitulada "Possibilidades para Ensinar Matemática na Perspectiva da Inclusão", apresentada pelo Professor Mestre, abordou práticas pedagógicas inclusivas para o ensino de matemática, e apresentou sugestões de atividades práticas de resolução de problemas, em que todos os estudantes podem participar e aprender a partir de suas potencialidades. De acordo com o palestrante, os estudantes devem ser protagonistas do seu processo de construção de conhecimentos, e, para tanto, o professor pode organizar situações em que os conteúdos sejam contextualizados, apresentar recursos e materiais concretos que auxiliem a todos os estudantes, independentemente de sua deficiência ou dificuldade de aprendizagem.

Os professores participantes questionaram sua função enquanto docentes, pois atividades práticas demandam muito tempo para sua preparação e desenvolvimento. Assim, colaborativamente, o palestrante convidou a todos para realizar um planejamento de aula, envolvendo uma situação-problema e conceitos matemáticos. A partir dessa atividade formativa os participantes compreenderam que desenvolver uma prática na perspectiva da educação inclusiva é possível, desde que seja planejada, com vistas às características dos estudantes, aos recursos disponíveis na escola e principalmente: que a avaliação dos estudantes seja formativa.

Nesse tipo de avaliação, segundo o palestrante, o erro não é utilizado para punir ou classificar os alunos, mas indica o que os estudantes podem vir a saber.

O palestrante ressaltou a importância do ato de planejar as aulas, pois, nesse momento o professor pode refletir sobre o currículo prescrito, em ação e oculto, de acordo com Libâneo (2001), e não utilizar apenas o livro como o orientador para seu trabalho.

Ao discutirem sobre as atividades, alguns professores perceberam que já desenvolvem ações coerentes com os pressupostos da educação inclusiva. A reflexão colaborativa, gerada através da palestra, que motivou os professores a repensar sobre o trabalho que desenvolvem, possibilitou a verificação de que é possível incluir todos os alunos nas aulas e que para isso a intenção ao planejar a aula deve ser a de valorizar as capacidades individuais de todos, valorizando os diferentes caminhos que todos seguem para aprender.

A reflexão dos professores participantes sobre os assuntos que foram abordados durante a experiência formativa foram importantes para que eles (re)pensassem sua própria prática pedagógica, refletindo sobre a educação inclusiva, e buscando as condições necessárias para trabalhar com todos os estudantes. 
Em termos das políticas educacionais, observamos que os professores conheciam alguns programas de ação do MEC, como a Sala de Recursos Multifuncionais, porém, não sabiam como solicitá-la para a Secretaria de Educação.

\section{DISCUSSÃO}

A experiência formativa estimulou os professores a refletirem sobre sua própria prática, bem como conhecer as possibilidades da escola pública para a inclusão de todos os estudantes, desde os aspectos legais, até os aspectos da prática.

A reflexão tem sido considerada como elemento essencial para formação de professores. De acordo com Liberali (1996, p.20) "refletir implica um processo de busca interior que pressupõe um distanciamento do senso comum". Considerando os ocorridos durante a experiência formativa proporcionada aos professores da rede municipal de educação do município do interior paulista, podemos observar que os professores conseguiram perceber determinado distanciamento entre a realidade da escola pública e as políticas de educação especial na perspectiva da educação inclusiva.

Assim compreenderam, que este distanciamento pode se estreitar com soluções como: recursos pedagógicos, tecnologia assistiva, e reivindicações de programas de ações do MEC.

\section{CONCLUSÃO}

Por meio da experiência formativa realizada, no âmbito da pesquisa de mestrado "Educação Inclusiva na Perspectiva do Trabalho Colaborativo: Desafio de uma Escola Pública", reforçou-se a necessidade de estabelecer parcerias entre universidades e escolas para compreender as especificidades que compõem a estruturação de uma escola inclusiva.

A pesquisa tem evidenciado que um trabalho colaborativo, que vise contribuir com as carências das escolas, pode trazer benefícios tanto para as perspectivas teóricas, quanto práticas, voltadas ao tema.

A experiência formativa permitiu aos professores participantes refletir e (re) pensar sua prática pedagógica, gerando uma consciência de que é possível reivindicar por políticas educacionais em prol do sistema, bem como tornar uma aula inclusiva dentro das possibilidades de uma escola pública.

\section{REFERÊNCIAS}

BRASIL: Ministério daEducação. Secretaria deEducação Especial.Política Nacional de Educação Especial na perspectiva da Educaçãolnclusiva.Brasília: MEC/SEESP, 2008.

CASTRO, Ruth C. M.; FACION, José R. A formação de professores. In: FACION, José R. (org). Inclusão Escolar e suas Implicações. 2 ed. Curitiba: Ibpex. p. 165 - 184, 2009.

GLAT, Rosana. Capacitação de professores: pré-requisito para uma escola aberta à diversidade. Revista Souza Marques, Rio de Janeiro, v. 1, n. 6, p. 16-22, 2000.

LAKATOS, Eva M.; MARCONI, Maria A. Fundamentos de Metodologia Científica: técnicas de pesquisa. 7 ed. São Paulo: Atlas, 2010.

LIBÂNEO, Carlos José. Organização e Gestão da escola: teoria e prática. Goiânia: Editora Alternativa, 2001. 
LIBERALI, Fernanda C. O Desenvolvimento Reflexivo do Professor. The ESP., São Paulo, v. 17, no 1, p. 19-37, 1996. Disponível em: http://revistas.pucsp.br/index.php/esp/article/view/9474/7040 Acesso em: 23 jul 2016.

SACRISTÁN José G.; GÓMEZ, Pérez I. A. Compreender e transformar o ensino. Porto Alegre: Artmed, 2000.

WEISS, A. M. L. A hora e a vez do professor: desafios da formação reflexiva através da informática na educação especial. 2003. 254f. Dissertação (Mestrado em Educação) - Programa de PósGraduação em Educação, Universidade do Estado do Rio de Janeiro, Rio de Janeiro, 2003. 